\title{
POLYNOMIALS WITH A SHARP CAUCHY BOUND AND THEIR ZEROS OF MAXIMAL MODULUS
}

\author{
HARALD K. WIMMER
}

Abstract. The moduli of zeros of a complex polynomial are bounded by the positive zero of an associated auxiliary polynomial. The bound is due to Cauchy. This note describes polynomials with a sharp Cauchy bound and the location of peripheral zeros.

Mathematics subject classification (2010): 11C08, 26C10, $15 \mathrm{~B} 48$.

Keywords and phrases: Zeros of polynomials, Cauchy bound, companion matrix, nonnegative matrix.

\section{REFERENCES}

[1] N. Anderson, E. B. SAFF, AND R. S. VARGA, On the Eneström-Kakeya theorem and its sharpness, Linear Algebra Appl., 28, (1979), 5-16.

[2] R. A. Horn and Ch. R. Johnson, Matrix Analysis, Cambrigde University Press, Cambridge, 1985.

[3] A. Hurwitz, Über einen Satz des Herrn Kakeya, Tôhoku Math. J. 4, (1913), 89-93; in: Mathematische Werke von A. Hurwitz, 2. Band, 627-631, Birkhäuser, Basel, 1933.

[4] M. MARden, Geometry of Polynomials, Mathematical Surveys of the American Mathematical Society, Vol. 3. Rhode Island, 1966.

[5] C. D. MeYER, Matrix Analysis and Applied Linear Algebra, SIAM, 2000.

[6] A. M. Ostrows KI, Solutions of Equations in Euclidean and Banach Spaces, Academic Press, New York, 1973.

[7] V. V. Prasolov, Polynomials, Springer, New York, 2004.

[8] Q. I. Rahman And G. SchmeIsser, Analytic Theory of Polynomials, Oxford University Press, Oxford, 2002.

[9] H. S. WiLf, Perron-Frobenius theory and the zeros of polynomials, Proc. Amer. Math. Soc., 12, (1961), 247-250. 